\title{
Calculation of the Characteristics of the Multi-gap Seal of the Centrifugal Pump, in Dependence on the Chambers' Sizes
}

\author{
Oleksandr Pozovnyi ${ }^{1}$, Andriy Zahorulko ${ }^{1}$, Jan Krmela ${ }^{2,3}$, Artem Artyukhov ${ }^{1}$, Vladimíra Krmelová ${ }^{3}$ \\ ${ }^{1}$ Faculty of Technical Systems and Energy Efficient Technologies, Sumy State University. RymskogoKorsakova \\ st.,2, 40007, Sumy. Ukraine. E-mail: aleksandrpozovnyi@gmail.com, a.zagorulko@omdm.sumdu.edu.ua, a.ar- \\ tyukhov@pohnp.sumdu.edu.ua \\ ${ }^{2}$ Faculty of Mechanical Engineering, J. E. Purkyně University in Ustí nad Labem. Pasteurova 3334/7, 40001 Ustí \\ nad Labem. Czech Republic. E-mail: jan.krmela@ujep.cz \\ ${ }^{3}$ Faculty of Industrial Technologies in Púchov, Alexander Dubček University of Trenčín. I. Krasku 491/30, 02001 \\ Púchov. Slovak Republic. E-mail: jan.krmela@tnuni.sk, vladimira.krmelova@tnuni.sk
}

The paper presents the results of an experimental research and a numerical calculation of a multi-gap seal of a centrifugal pump. The experimental research allowed to obtain the characteristics' performance of the multi-gap seal at different operating modes, in dependence on the axial size of the chambers, pressure distributions' changes, and a leakage from the seal. Using finite volume methods, values of radial hydrostatic forces, pressure distributions and leakage values were obtained. The results of the numerical calculation were compared with the results of the experiment, which showed that they matched.

Keywords: multi-gap seals, hydrostatic forces, a leakage, an experimental and numeral research

\section{Introduction}

Providing the necessary sealing of centrifugal pumps is still a significant issue. Gap seals are widely used as multi-stage, and in some cases, as end seals. Besides that, throttles can be a part of the designs of modern sealing systems performed to balance devices. In recent years, many studies have been aimed at increasing the overall efficiency of centrifugal pumps by reducing a leakage through the end and intermediate seals at high values of pressure variations and rotor speeds. Therefore, to reduce the mass flow rate, the seal with two or three throttle gaps as the front seals of the impeller are used. The construction of such a seal is maintained by gradually located throttles connected with each other by chambers (Fig. 1), the size of which affects the hydrostatic stiffness of the seal and can cause the rotor vibration.

A number of scientific articles are devoted to the study of single-gap seals of centrifugal pumps [1 - 6], nevertheless, and for the reduction of the volume flow rate, multi-gap seals are used. The analysis showed that such types of constructions on hydraulic resistance are equivalent to two or three gradually placed throttles, therefore, at the same axial overall dimensions the mass flow rate is reduced. In work [1], the possibility of multi-gap seals that cause increased vibration of the rotor is described. Though, the study of the effect of cameras' size on the hydrostatic force of seals is limited and should be considered.

An analytical calculation of the hydrodynamic cha- racteristics of seals is associated with certain difficulties [7]. Solving equations describing the three-dimensional flow of liquid through the seal construction, at present time, cannot be obtained in a closed analytical form. Each researcher in solving the given task is forced to introduce assumptions and neglect the influence of various factors.

Recently, more and more computer modelling and computational researches have been increasingly used by software complexes based on numerical finite-volume methods, mass transfer, and experimental planning[8,9]. Thus, it may be noted that the experimental and numerical analysis of multi-gap seals is currently relevant.

Numerical analysis of the hydrostatic forces of multi-gap seals requires solving the hydrostatic task in three-dimensional formulation with the help of methods of computational hydrodynamics with the corresponding verification of the obtained results of numerical studies by comparing them with the results of the physical experiment.

\section{Numerical calculation}

Modelling of fluid flow in a multi-gap seal using the finite volumes' method: during the calculation research with the help of the ANSYS CFX software complex the problem of hydrostatic fluid flow through the multi-gap seal was solved. The complete model of fluid flow, which includes three consecutively placed throttles, connected by two chambers, was considered (Fig. 1). The calculation grid was created in 
the ANSYS Meshing program using the Sweep method, which allows to construct a deployed grid on a model that rotates around the axis where the output and target boundaries have a common topology [7, 12]. 30 elements were set according to the thickness of the gap. As a result, the calculation grid consisted of about 7.5 million elements. The thickening of the calculation grid in the parietal layers was carried out. The quality of the grid was controlled from the analysis of the distribution of the dimensionless parameter $Y+$ along the walls of the flowing part, which varied from 20 to 50, and the visual control, in order to prevent the presence of excessively elongated or wry elements. For calculation, high Reynold's $k-\varepsilon$ model of turbulence with an intensity of $5 \%$ input was used. This model is semi-empirical and uses two differential equations for the closure of the Reynolds equations, describing the transfer of the kinetic energy of turbulence $\mathrm{k}$ and the velocity of dissipation of turbulent energy $\varepsilon$. The boundary conditions are set: the water temperature is $20^{\circ} \mathrm{C}$, the pressure of the liquid supply at the inlet is $1 \mathrm{MPa}$, the pressure at the outlet with the seal is $0 \mathrm{MPa}$. The walls remained at stationary state.
During the calculation, the dimensions of the chamber (Fig. $2,1_{2}=1_{4}$ ) changed from 0.4 to $4 \mathrm{~mm}$ and at the radial displacement of the shaft $-0.08 \mathrm{~mm}$. The main thermodynamic properties of water: temperature, coefficient of dynamic viscosity and density are assumed to be constant [11 - 14].

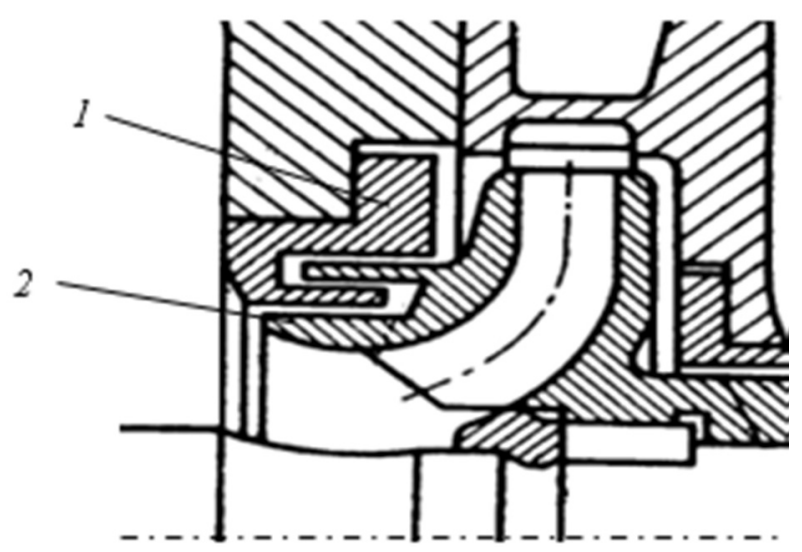

Fig. 1 The stage of a centrifugal pump: 1 - a front threespray seal of a working wheel, 2 - a working wheel

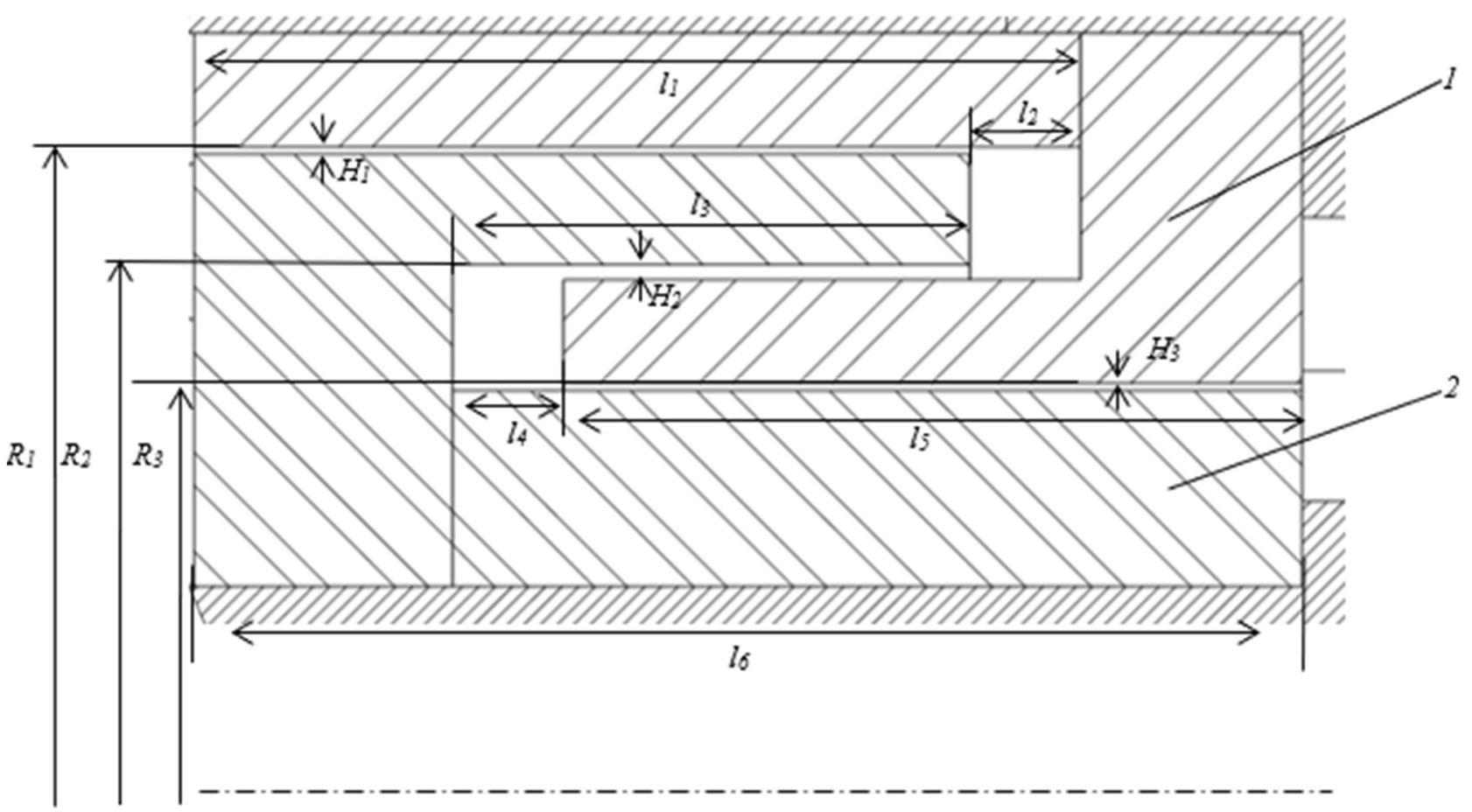

Fig. 2 The scheme of a three-spray seal ( 1 - a stator wall, $2-$ a shaft wall) $l_{1}=24 \mathrm{~mm}, l_{2}=l_{4}=3 \mathrm{~mm}, l_{3}=11 \mathrm{~mm}, l_{5}=$ $23 \mathrm{~mm}, l_{6}=30 \mathrm{~mm}, \mathrm{R}_{1}=44.4 \mathrm{~mm}, \mathrm{R}_{2}=41.2 \mathrm{~mm}, \mathrm{R}_{3}=38 \mathrm{~mm}, H_{1}=0.2 \mathrm{~mm}, H_{2}=0.2 \mathrm{~mm}, 0.4 \mathrm{~mm}, H_{3}=0.2 \mathrm{~mm}$

\section{Results of numerical calculation}

At first, the model of a three-gap seal with the equal radial dimensions of the gaps I-variant $\left(H_{1}=H_{2}\right.$ $=H_{3}$ in Fig. 2) was considered. But due to the fact that the pressure on the first chamber from the inlet is aligned unsatisfactorily (Fig. 3) and there may be rotor vibrations due to changes in the hydrostatic force value that should balance the rotor, further the model of the seals with a two times bigger second gap II-variant $\left(H_{2}=2 H_{1}=2 H_{3}\right.$ in Fig. 2) was considered in relation to the first and third (Fig. 4) in order to equalize pressure on it at a given displacement of the shaft $e=0.08$ $\mathrm{mm}$. 


\section{Pressure}
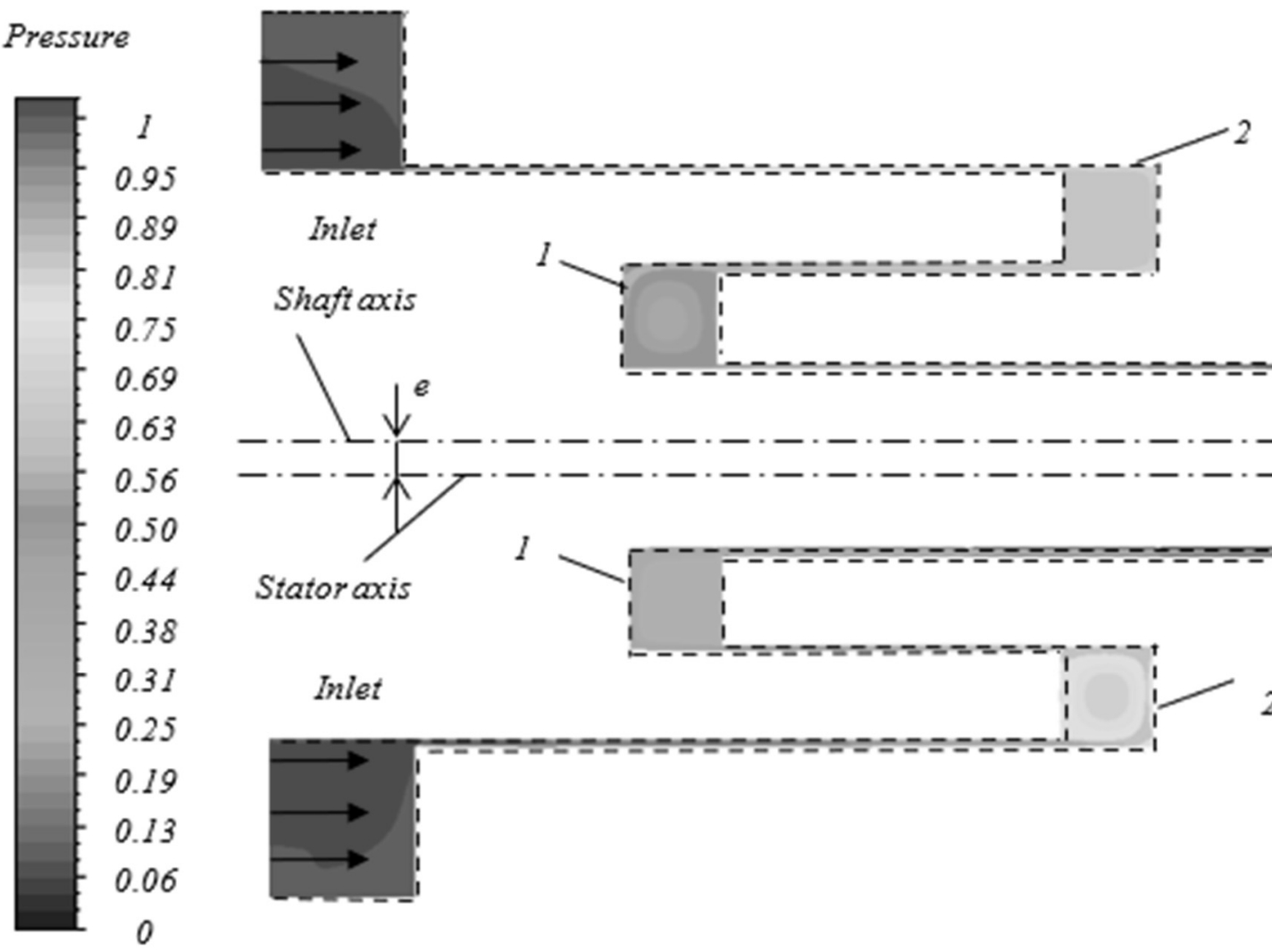

Statoraxis

I

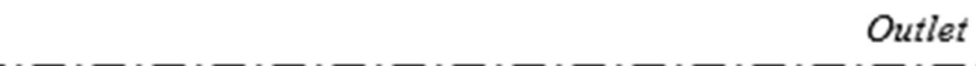

Outlet

$\mathrm{MPa}$

Fig. 3 Pressure distribution in a three-gap seal with gaps I-variant, with eccentricity $\left(e=0.08 \mathrm{~mm}, l_{2}=l_{4}=3 \mathrm{~mm}\right): 1-a$ shaft wall, 2 - a stator wall

Also, the influence of the chambers' size on the hydrostatic forces and the leakage from the seal was considered (chambers' indication $-K$ was introduced, where $l_{2}=l_{4}$, Fig. 2). Values of calculations from the ANSYS software system are at Tab. 1.
Pressure
$\begin{aligned} & I \\ & 0.94 \\ & 0.88 \\ & 0.81 \\ & 0.75 \\ & 0.69 \\ & 0.63 \\ & 0.56 \\ & 0.50 \\ & 0.44 \\ & 0.38 \\ & 0.3 \\ & 0.25 \\ & 0.19 \\ & 0.13 \\ & 0.06 \\ & 0\end{aligned}$

$\mathrm{MPa}$

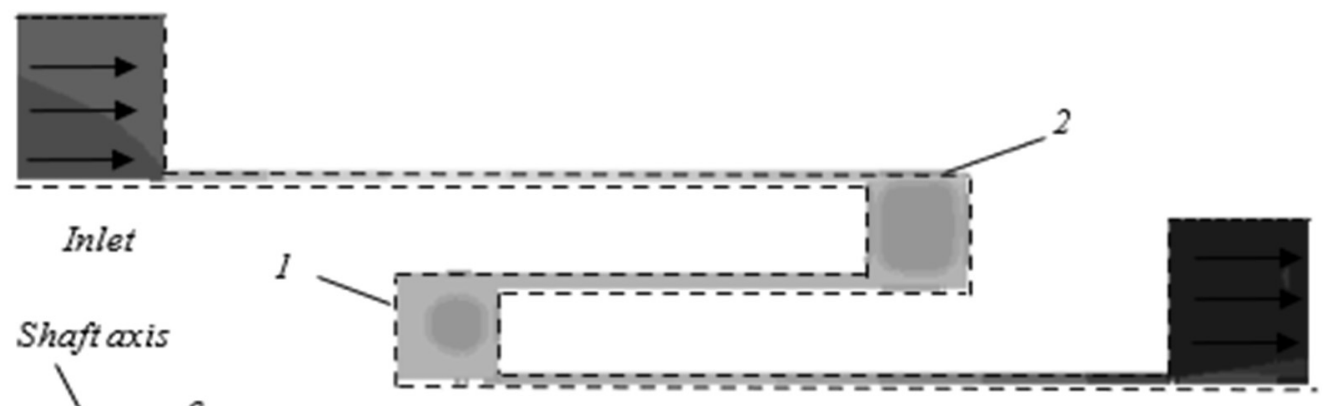

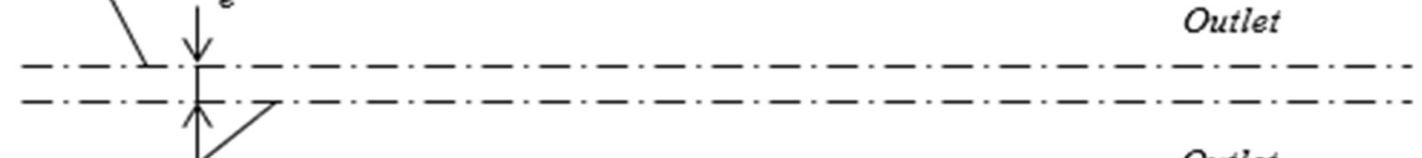

Outlet

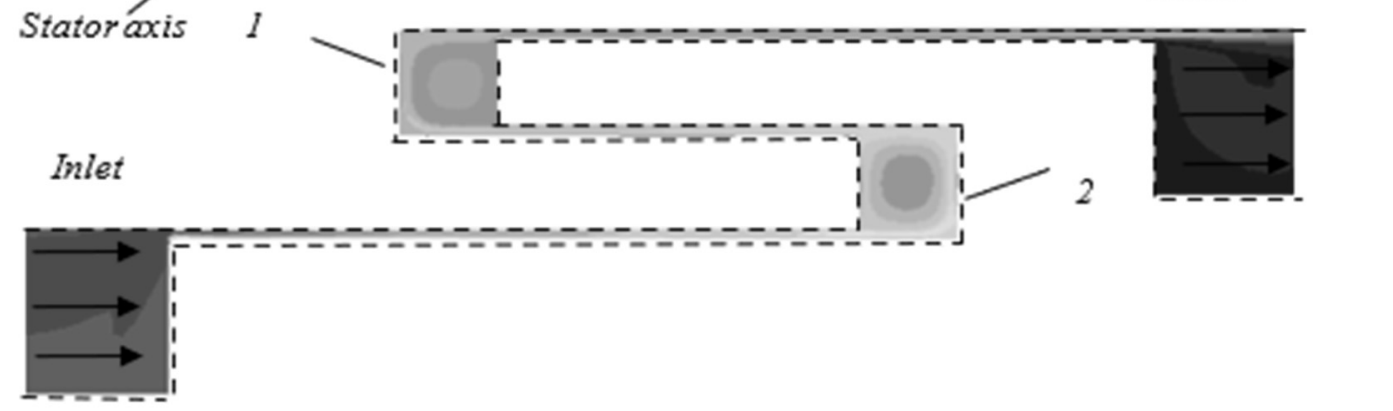

a) $K=3 \mathrm{~mm}$ 


\section{Pressure}
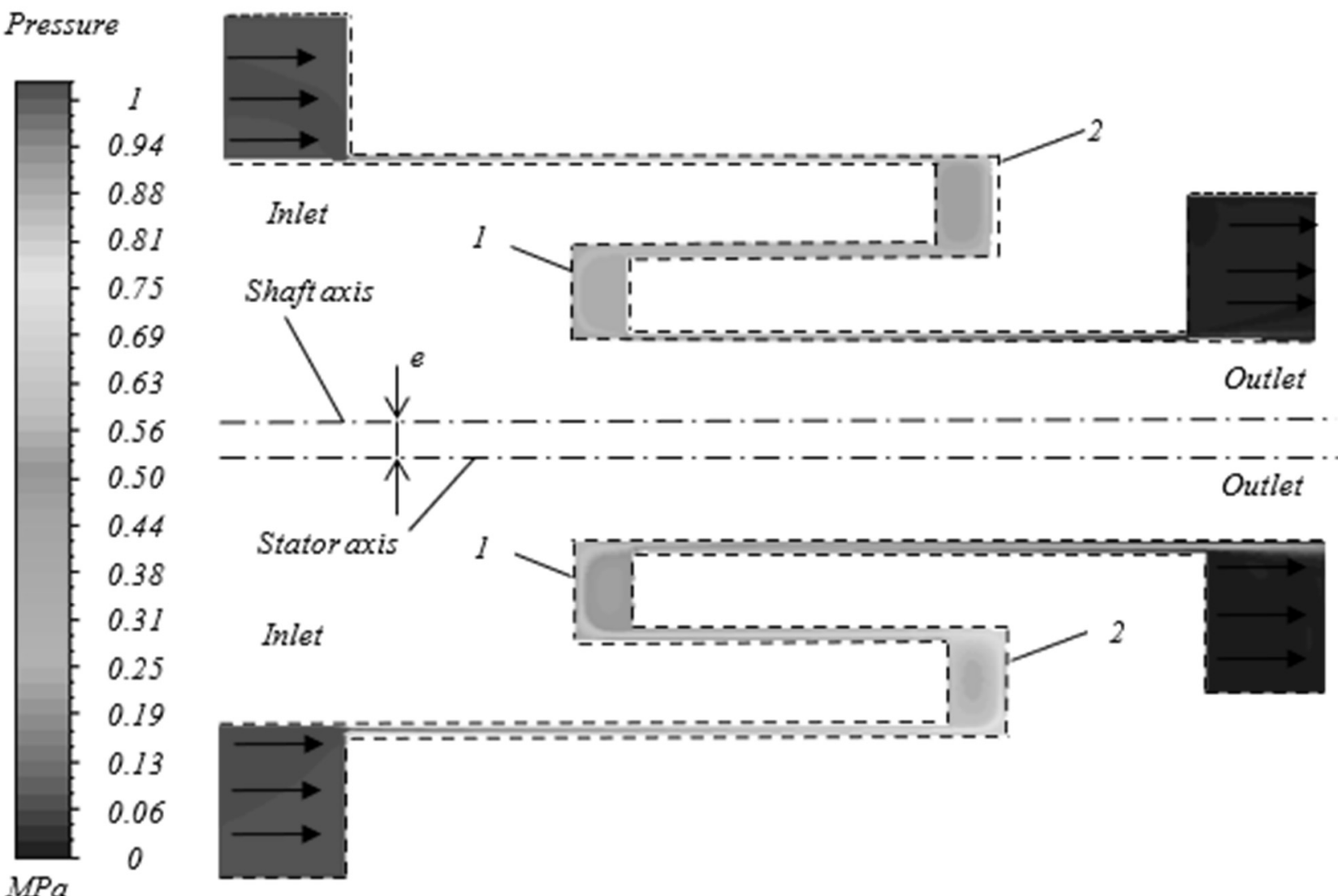

$\mathrm{MPa}$

1
0.94
0.88
0.81
0.75
0.69
0.63
0.56
0.50
0.44
0.38
0.31
0.25
0.19
0.13
0.06
0

b) $K=2 \mathrm{~mm}$

\section{Pressure}
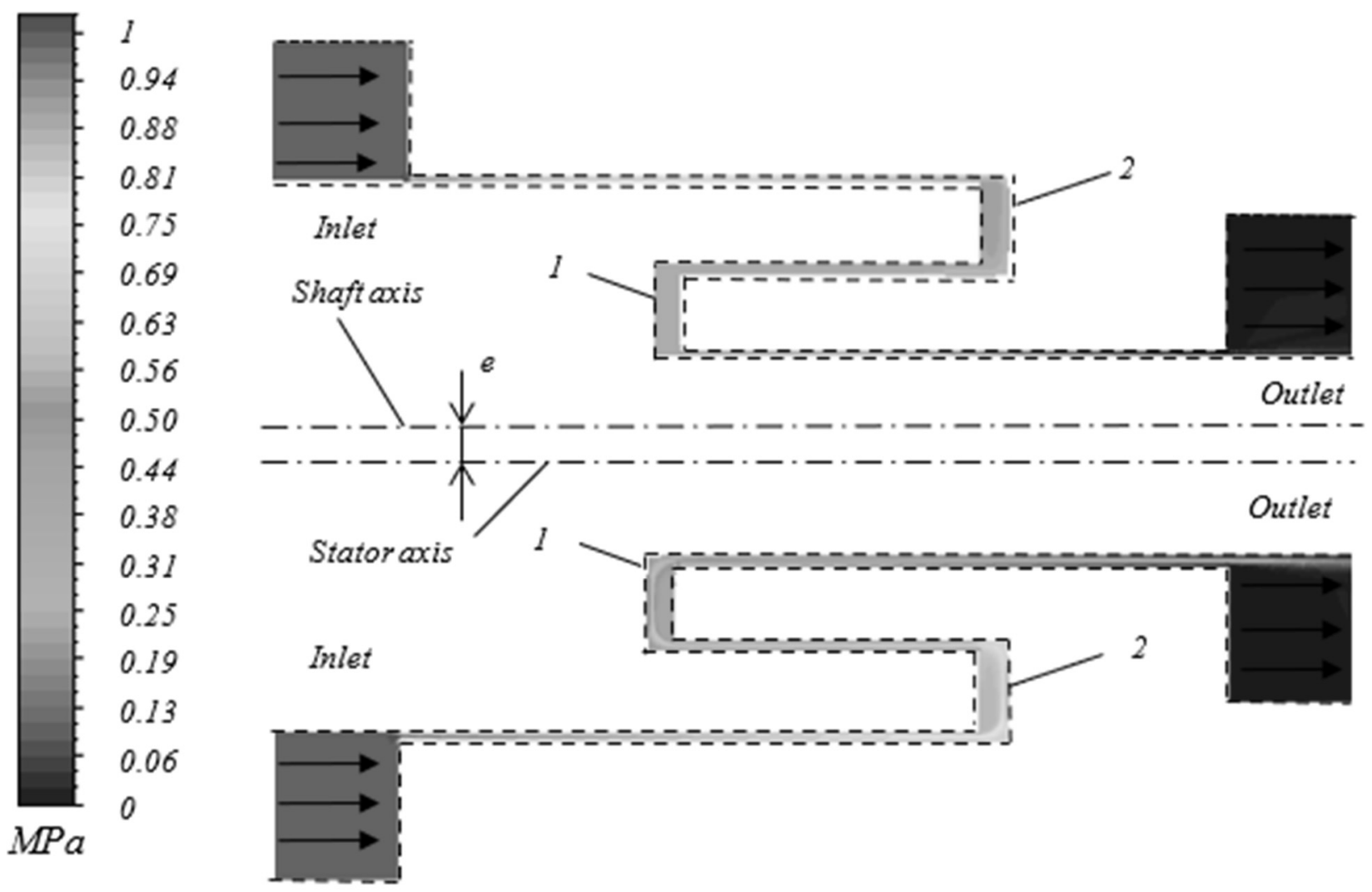

c) $K=1 \mathrm{~mm}$ 


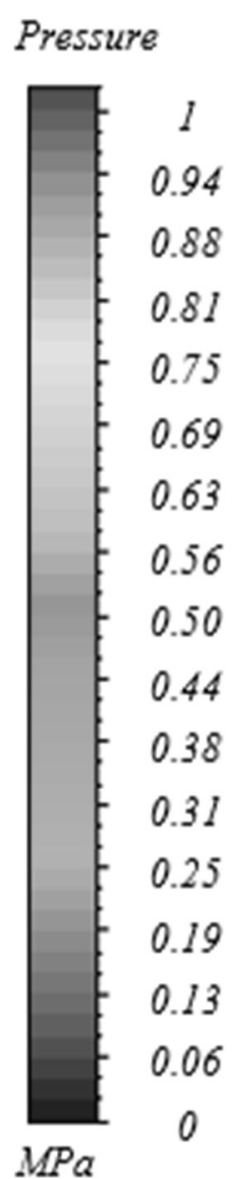

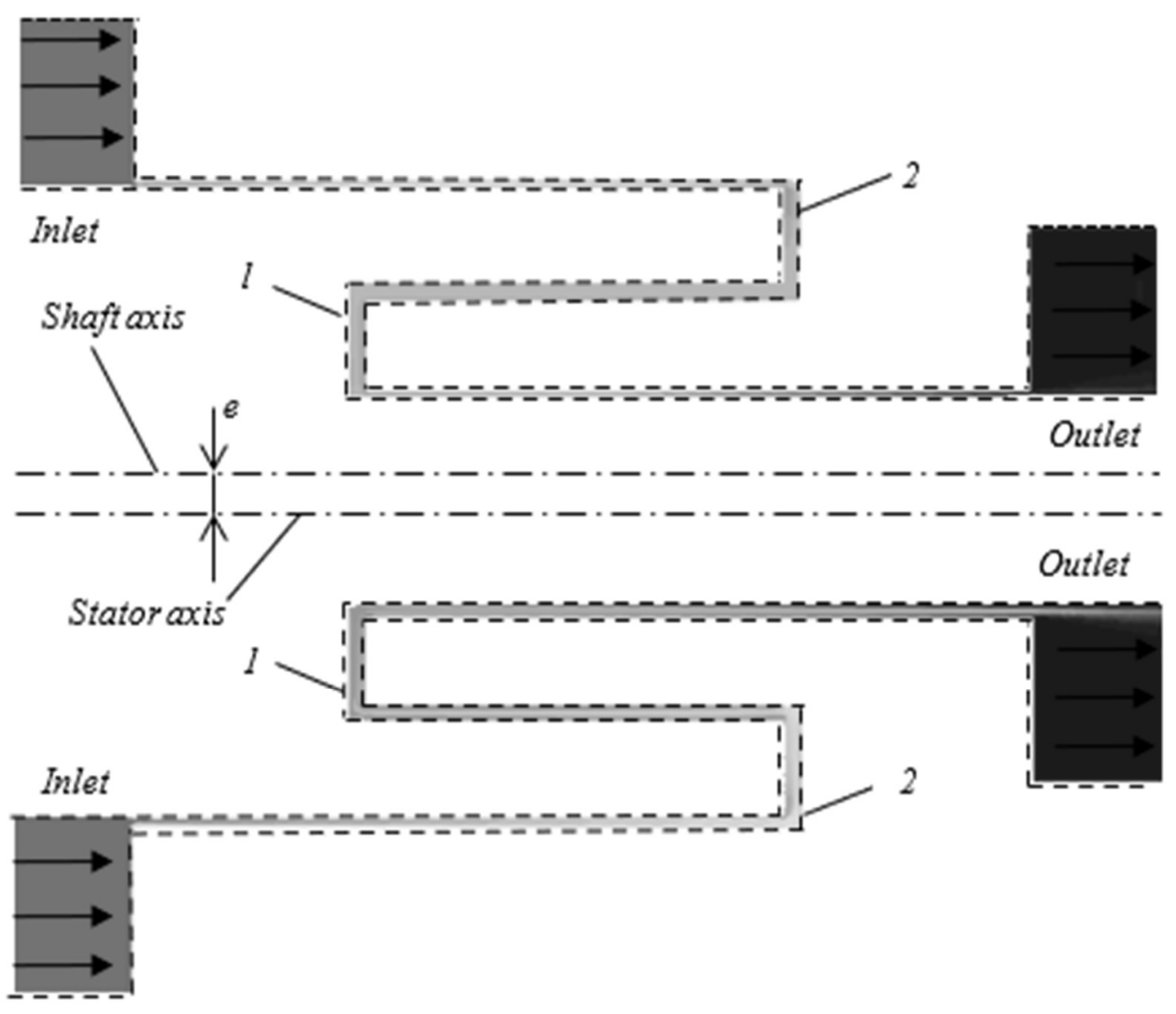

$$
\text { d) } K=0.5 \mathrm{~mm}
$$

Fig. 4 Pressure distribution in three-gap seals with gaps II-variant, with eccentricity $(e=0.08 \mathrm{~mm}): 1-a$ wall shaft; $2-$ a stator wall

Tab. 1 Values of calculations from the ANSYS software system

\begin{tabular}{|c|c|c|c|c|c|}
\hline Gaps size & $\mathrm{K}[\mathrm{mm}]$ & $\mathrm{F}[\mathrm{N}]$ & $\mathrm{Q}\left[\mathrm{m}^{3} \cdot \mathrm{s}^{-1}\right]$ & $\mathrm{P}_{1}[\mathrm{MPa}]$ & $\mathrm{P}_{2}[\mathrm{MPa}]$ \\
\hline I-variant & 3 & 97 & 0.78 & 0.65 & 0.55 \\
\hline \multirow{5}{*}{ II-variant } & 4 & -58 & 0.94 & 0.58 & 0.54 \\
\cline { 2 - 6 } & 3 & -57 & 0.93 & 0.55 & 0.53 \\
\cline { 2 - 6 } & 2.5 & -53 & 0.93 & 0.58 & 0.54 \\
\cline { 2 - 6 } & 2 & -48 & 0.92 & 0.60 & 0.52 \\
\cline { 2 - 6 } & 1 & -40 & 0.94 & 0.63 & 0.53 \\
\cline { 2 - 6 } & 0.9 & -32 & 0.93 & 0.62 & 0.54 \\
\cline { 2 - 6 } & 0.8 & -27 & 0.92 & 0.63 & 0.54 \\
\cline { 2 - 6 } & 0.7 & -22 & 0.92 & 0.65 & 0.55 \\
\cline { 2 - 6 } & 0.6 & -11 & 0.91 & 0.64 & 0.58 \\
\cline { 2 - 6 } & 0.5 & 0 & 0.90 & 0.67 & 0.57 \\
\hline
\end{tabular}

By the value of radial forces, a graph was constructed, depending on the axial size of the chambers, and the approximation by the least squares' method was carried out.

From the graph, it is evident that with the size $K \leq$ $0.5 \mathrm{~mm}$ the hydrostatic force has a positive value, that is, it decenters the rotor, so it is necessary that the axial size of the chambers is more than $0.5 \mathrm{~mm}$. At values $0.5<K<1 \mathrm{~mm}$ the magnitude of the hydrostatic force increases sharply, and at $K>1 \mathrm{~mm}$ its value increases not so intensive, so the difference between forces at $K$ $=1 \mathrm{~mm}$ and $K=0.9 \mathrm{~mm} 20 \%$, at $K=1 \mathrm{~mm}$ and $K=2$ $\mathrm{mm}$ is $16.7 \%$. For values $K>3 \mathrm{~mm}$, the force is almost unchanged. 


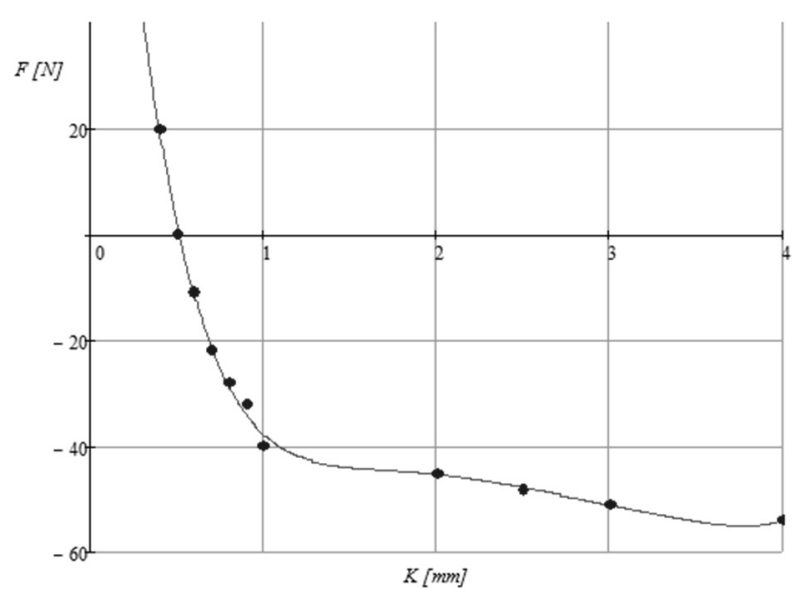

Fig. 5 The graph of radial force dependence on the axial size. of chambers

\section{Experimental research}

Tests of multi-gap seal were carried out on the basis of the research and development laboratory of vibration-reliability and leak proofness of centrifugal machines of the Department of General Mechanics and Machine Dynamics of Sumy State University on an experimental stand for the study of hydrodynamics of throttles in accordance with the program and test methods. The necessary conditions for the installation operation are provided by a special system of preparation and supply of sealing medium - liquids (water). To ensure the effectiveness of experimental researches, taking into account the need for registration of fleeting processes and based on the capabilities of modern electronic computers, the stand is equipped with a specially created a universal automated measuring system. It allows to record automatically and accumulate the results of measurements of all parameters controlled during the research process. Before assembling the experimental unit, the geometry of the seal was measured and two pressure sensors were installed in the first chamber. Fig. 6 shows the scheme of the experimental unit of the installation with a three-gap seal. A pair of seals is created by the stator bushing 2, fixed in the cylinder of the test head, and the rotor bushing 6 , fixed by a nut on the shaft. The rotary bushing has threaded holes at the ends for fastening the weights that allow to create an artificial imbalance, to ensure that the center of the mass of the rotor shifts within $0-0.2 \mathrm{~mm}$. Pressure measurements were carried out at the inlet and in the first chamber in two places, depending on the eccentricity.

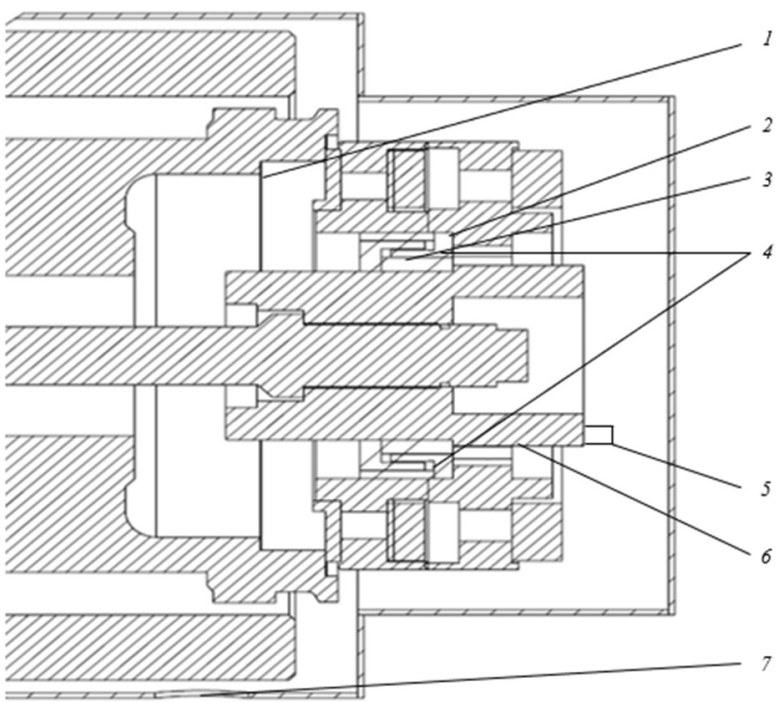

Fig. 6 Scheme of an experimental unit: $1-$ a location of pressure sensors at the inlet, 2 - a stator, 3 - a multi-gap seal, 4 - a location of pressure sensors in the chamber (P1, P2), 5-an imbalance, 6-a shaft, 7 - a leakage measure-

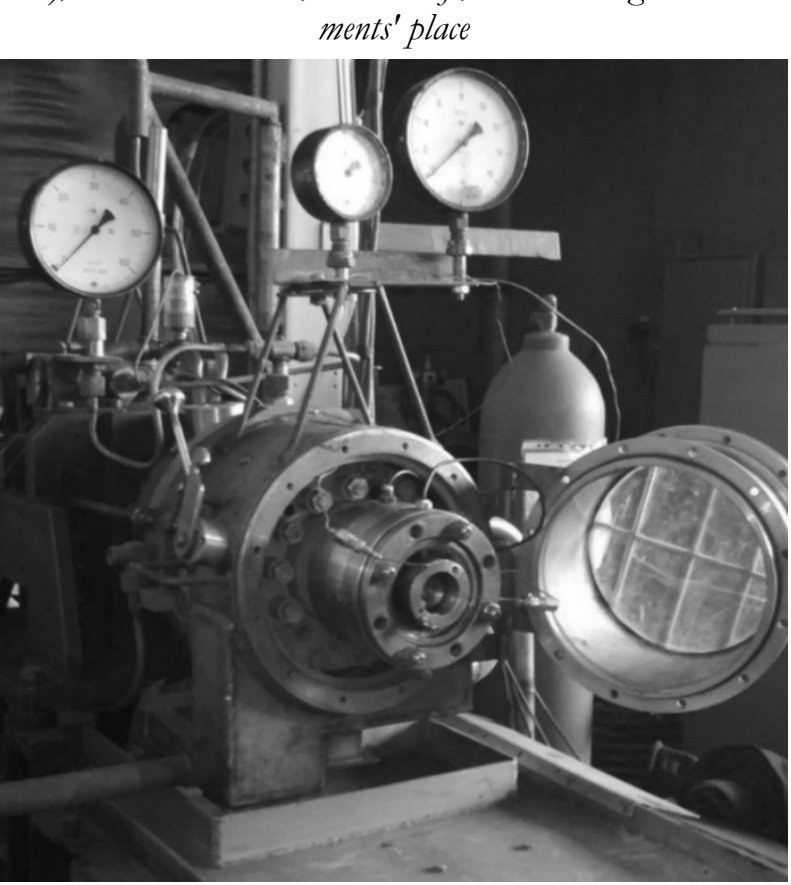

Fig. 7 Surface of the experimental installation

Tab. 2 shows the results of the physical experiment with a two times bigger second gap II-variant $(H 2=$ $2 \mathrm{H} 1=2 \mathrm{H} 3$ in Fig. 2 ) in relation to the first and third in order to equalize the pressure on it with a given displacement of the shaft $e=0.08 \mathrm{~mm}$.

Tab. 2 Values of the Experimental Research

\begin{tabular}{|c|c|c|c|c|}
\hline Sealing construction & $\mathrm{K}[\mathrm{mm}]$ & $\mathrm{Q}\left[\mathrm{m}^{3} \cdot \mathrm{s}^{-1}\right]$ & $\mathrm{P}_{1}[\mathrm{MPa}]$ & $\mathrm{P}_{2}[\mathrm{MPa}]$ \\
\hline \multirow{3}{*}{ II-variant } & 3 & 0.82 & 0.65 & 0.52 \\
\hline \multirow{3}{*}{ II-variant } & 3 & 0.95 & 0.53 & 0.50 \\
\cline { 2 - 5 } & 2 & 0.95 & 0.62 & 0.52 \\
\cline { 2 - 5 } & 1 & 0.94 & 0.62 & 0.53 \\
\cline { 2 - 5 } & 0.5 & 0.86 & 0.63 & 0.52 \\
\hline
\end{tabular}




\section{Conclusion}

The paper considers the effect of the change of the axial size of the chambers of the multi-gap seal on the operation of the centrifugal pump by means of experimental research and numerical experiment. The experimental research allowed to obtain the performance characteristics of the seal at different operating modes, depending on the change in the size of the chambers, as a result of which the pressure distribution and the leakage from the seal also changed. As a result of the numerical experiment, radial hydrostatic forces were obtained and the boundary of the radical change of radial force was determined, this occurs when the values of the axial size of the chambers are $K<1 \mathrm{~mm}$.

Comparison of the results of the experiment and the numerical calculation showed their satisfactory matching, the maximum divergence of the leakage is $5.1 \%$, and the values of pressure is $7.1 \%$.

Analysis of the research results showed that there is a possibility of increasing the hydrostatic power of the multi-gap seal without the increasing the amount of volumetric losses due to the change in the axial size of the chambers.

\section{Acknowledgments}

This research work had been supported by the Cultural and Educational Grant Agency of the Slovak Republic (KEGA), project No. KEGA 002TnUAD-4/2019.

\section{References}

[1] MARTSYNKOVSKYY, V. (2005). Annular Seals: Theory and Practice. Sumy State University, Sumy.

[2] MARTSYNKOVSKYY, V. (2012). Dynamics of a Centrifugal Pump Rotors. Sumy State University, Sumy.

[3] MARTSINKOVSKYY, V. and others. (2018). Ecological Safety of Operation of Compressor and Pumping Equipment. Sumy State University, Sumy.

[4] LOMAKIN, A. (1966). Centrifugal and Axial Flow Pumps. PublishingHouse, Moscow.

[5] TARELNYK, V., MARTSYNKOVSKYY, V. (2014). Upgrading of Pump and Compressor Rotor Shafts Using Combined Technology of Electroerosive Alloying. In: Applied Mechanics and Materials, Vol. 630, pp. 397-412. HERVICON 2014.

[6] VIJAYKUMAR, A., MORRISON, G. (2010). Numerical Simulation of the Flow Field in a Statically and Dynamically Eccentric Annular
Seal with Non-circular Whirl Orbits. FEDSM, 1(PARTS A, B AND C), pp. 731-761. Canada.

[7] CHILDS, D. W. (1983). Finite Length Solutions for Rotordynamic Coefficients, of Turbulent Annular Seals. In: Journal of Tribology, Vol. 105, No. 3, pp. 437-444. Texas.

[8] KOVÁČIKOVÁ, P., VAVRO, J., VAVRO jr., J., DUBEC, A. (2018). Measuring of VibrationDamping Properties of Cast Iron. In: Manufacturing Technology, Vol. 18, No. 1, pp. 5759. ISSN 1213-2489. DOI: 10.21062/ujep/53.2018/a/12132489/MT/18/1/57

[9] SOUKUP, J., KRMELA, J., KRMELOVÁ, V., SKOČILASOVÁ, B., ARTYUKHOV, A. (2019). FEM Model of Structure for Weightlifting in CrossFit in Terms of Material Parameters. In: Manufacturing Technology, Vol. 19, No. 2, pp. 321-326. ISSN 1213-2489. DOI: 10.21062/ujep/290.2019/a/1213-

2489/MT/19/2/321

[10] KORCZAK, A., MARTSYNKOVSKYY, V., GUDKOV, S. (2012). Estimating Influence of Inertial Resistance of Throttle for Hydraulic Balancing Device on Rotor Axial Vibration. In: International Scientific and Engineering Conference on Hermetic Sealing, Vibration Reliability and Ecological Safety of Pump and Compressor Macbinery. Procedia Engineering, Vol. 39, pp. 261-274. HERVICON 2011.

[11] MARTSYNKOVSKYY, V., DEINEKA, A., KOVALENKO, V. (2017). Evaluation of Rotor Axial Vibrations in a Turbo Pump Unit Equipped with an Automatic Unloading Machine. In: IOP Conference Series: Materials science and Engineering.

[12] GAO, R. (2012). Computational Fluid Dynamic and Rotordynamic Study on the Labyrinth Seal. Ph.D. Dissertation in Mechanical Engineering. Virginia Polytechnic Institute and State University.

[13] POZOVNYI, O., DEINEKA, A., LISOVENKO, D. (2020). Calculation of Hydrostatic Forces of Multi-gap Seals andIts Dependence on Shaft Displacement. In: Lecture Notes in Mechanical Engineering, Advances in Design, Simulation and Manufacturing II 661.

[14] KOVÁČIKOVÁ, P., VAVRO, J., VAVRO jr., J., DUBEC, A. (2018). Microstructure Evaluation of Ductile Cast Iron and Numerical Modal Analysis. In: Manufacturing Technology, Vol. 18, No. 4, pp. 597-599. ISSN 1213-2489. DOI: $\quad 10.21062 /$ ujep/144.2018/a/12132489/MT/18/4/597 